\title{
Financial incentives to improve the quality of primary care in the UK: predicting the consequences of change
}

Martin Roland, Stephen Campbell, Nan Bailey, Diane Whalley and Bonnie Sibbald National Primary Care Research and Development Centre, University of Manchester, Williamson Building, Manchester, UK

\begin{abstract}
Up to $20 \%$ of additional income is being provided to UK general practitioners (GPs) to improve quality of care, through a complex set of quality indicators which relate principally to chronic disease management and organizational aspects of care. Using data from semi-structured interviews with a purposive sample of $20 \mathrm{GPs}$ and responses from 1035 GPs to a questionnaire survey (53\% response rate), we describe the initial impact of these incentives. GPs are employing more staff, especially nurses and data entry clerks, and computerizing their clinical records. Patients are more frequently seen in disease-oriented clinics run by nurses. While the health gains associated with the incentives may be realized, GPs predict that there may be unintended consequences, including reduced continuity of care, care fragmentation, neglect of unincentivized conditions, and the risk of damage to their internal motivation.
\end{abstract}

Key words: financial incentives; general practitioners; primary care; quality of care

Received: May 2005; accepted: October 2005

\section{Introduction}

In April 2004, general practitioners (GPs) in the UK entered into a contract with the government in which up to $20 \%$ of their pay relates to the quality of care they provide. Points are awarded against a complex set of 136 quality indicators. There are three main groups of indicators: clinical care (550 points), practice organization (184 points), and patient experience (100 points). Additional points up to a total of 1050 are available for achieving high rates of preventive procedures, for providing good access, and for achieving high levels across all indicators.

The clinical indicators relate to 10 chronic conditions chosen because of their prevalence, or their importance in terms of burden of disease. Generally, more points are available for the intermediate outcomes (eg, level of blood pressure achieved) than

Address for correspondence: Martin Roland, National Primary Care Research and Development Centre, University of Manchester, Williamson Building, Oxford Road, Manchester M13 9PL, UK. Email: m.roland@manchester.ac.uk for the process measures (eg, whether blood pressure had been taken or not), reflecting the increased difficulty of achieving intermediate outcomes. In order not to distort normal clinical practice and to reduce the risk of cream skimming, GPs may exclude patients from both the numerator and denominator for any indicator if they meet one of a number of exclusion criteria, for example, patients who do not attend for review despite three written reminders, or patients in whom the GP judges that an indicator is clinically inappropriate. Organizational indicators are included in five domains: records and information about patients, patient communication, education and training, medicines management, and practice management.

The incentives in the patient experience section relate to the use of surveys in the doctors' own practices and to length of consultations. Doctors are rewarded for surveying their patients and for acting on the results. There is an additional incentive for GPs to involve their patients in discussion about survey results. For consultation length, there is an incentive for practices whose routine booking interval is 10 minutes or more. 
The number of points available for the indicators is intended to reflect the workload required to provide care of the required standard. Points translate into money, and the quality payments amount to up to $£ 42000$ per GP, or over $£ 1$ billion in total per annum. This represents around $20 \%$ of the government's total family practice budget, and approximately $90 \%$ of this represents new payments. The figures are gross and therefore do not take account of the additional costs (eg, of employing nurses) that the GPs may incur in order to deliver the high standards of care. The increases in take home pay for individual physicians will therefore depend on the extent to which they have already invested in quality systems in their practices. We have described this framework in more detail elsewhere (Roland, 2004). The indicators themselves are listed at http://www.nhsconfed.org/docs/annex_a_quality_ indicators.doc, and guidance on the evidence behind the indicators and their application is at www.nhsconfed.org/docs/quality_and_outcomes_ framework_guidance.pdf.

The introduction of these performance incentives is part of a general trend in the management of public services away from placing implicit trust in individuals towards active management of performance (Checkland et al., 2004; Harrison and Smith, 2004). Given evidence of substantial variation in quality of primary care (Seddon et al., 2001), it is now widely accepted by policy makers that, while professional motivation is necessary to achieve uniform high standards, it is not sufficient (Institute of Medicine, 2001; Washington DC National Academy Press, 2001). Past experience of financial incentives for family physicians in the UK suggests that such incentives can have a significant impact on rates for cervical cytology and immunization (Baker and Middleton, 2003; Middleton and Baker, 2003). However, the impact of financial incentives on physician performance are variable and contingent on factors such as the design of the incentive and the context in which the incentive is used (ChaixCouturier et al., 2000) and the impact of financial incentives may be reduced when physicians perceive their income to be sufficient (Rizzo and Blumenthal, 1996; Rizzo and Zeckhauser, 2003).

In a previous study, we examined a primary care incentive scheme that covered a similarly broad range of clinical areas (Spooner et al., 2001). This scheme which incentivized chronic disease management drew widespread support from local GPs, even though involvement in the scheme appeared to cost many GPs more than the rewards offered. However, there was concern among participating GPs that there was potential for neglect of unincentivized clinical areas, an effect described as 'tunnel vision' by Smith in his review of the unintended consequences of performance incentives (Smith, 1995). In our earlier study (Spooner et al., 2001) we also suggested that incentives were most likely to produce their anticipated results when the managerial incentives were aligned with the GPs' own professional values.

Despite the complexity of the quality framework being introduced in UK primary care, it still covers only a small part of the daily work of a GP, and is in that sense not a 'complete' contract (Sheaff and Lloyd-Kendall, 2000). High performance in nonincentivized areas will therefore continue to rely on professionalism or 'moral motivation', that is, behaviours that are based on internal norms and strengthened by the socialization process of professional training. Of particular concern is the evidence from the psychological literature that providing external incentives may reduce internal motivation (Deci et al., 1999). Changes in internal motivation might not only change behaviours, but also alter doctors' values such that patient and public interests might become subordinate drivers to personal financial gain. Set against this, the performance indicators in the current UK contract were negotiated with the profession and in substantial part drew on measures developed by professional organizations. They might therefore act both as extrinsic and moral motivators, thereby mitigating unintended consequences that might otherwise occur (Casalino, 1999).

In this article, we describe initial changes and predict the consequences that may follow from the introduction of quality incentives by drawing on two sets of data: interviews with a purposive sample of 20 GPs carried out in early 2004, and the results of a postal survey of a nationally representative sample of 1950 family practitioners carried out during the same period. Although the incentives in the new contract were introduced in April 2004, GPs had known the outline of the new incentives since summer 2002, and the detail since summer 2003. The responses to the interviews and questionnaires therefore reflected their experience following several months of preparation for the new contract. 


\section{Methods}

\section{Qualitative data}

Telephone interviews with a purposive sample of 20 GPs were conducted by two research staff (SC, NB). These GPs were selected from 42 practices taking part in a longitudinal assessment of quality of care (http://www.npcrdc.man.ac.uk/ Research Detail.cfm?ID=118\&txtSearch=quip). GPs were selected for interview to provide maximum variation in a range of characteristics including age, sex, practice size, geographical locality, and educational experience. A semi-structured interview schedule covered general opinions on the quality incentives, changes in practice organization, factors inhibiting and facilitating change, and how changes might affect staff roles. The interviews were conducted between January and March 2004 with each interview lasting approximately $45 \mathrm{~min}$. Interviews were tape-recorded and transcribed. Transcripts were coded independently by two researchers and used as the basis for a thematic analysis with themes decided in discussion by the two researchers (SC,NB). In analysing the data, the researchers identified responses that related to the quality incentive framework: responses relating to other aspects of the contract are not reported in this article.

\section{Quantitative data}

The survey included a random sample of 1950 GPs in England drawn from a Department of Health database. The initial mailing was undertaken in February 2004, with up to two further mailings to non-responders at three-week intervals. One thousand and thirty-five GPs $(53.1 \%)$ provided usable responses to the questionnaire.

The survey questionnaire asked GPs about their current personal and practice situation, and their attitudes towards their job in terms of satisfaction, stressors, design and intended changes to their work commitment. Also included was a series of questions asking what impact they thought the new contract would have on various aspects of their working life and on quality of care in their practice. The questions were asked about the contract as a whole. While quality incentives form an important part of the contract, they are not the whole of it. Responses about quality of care are likely to relate primarily to the quality framework, but responses about more general aspects of work life may relate to other changes, for example, removal of the responsibility for arranging out of hours cover for practice patients.

Associations between doctors' views on the anticipated impact of the new contract and their age, gender, and practice characteristics were evaluated through a series of ordered logit regression models. The dependent variable in each model was one of the anticipated impact items, with scores ranging 1 (decrease a lot) to 5 (increase a lot). The independent variables were constant across the eight models and included: sex (male versus female); age (40-49, 50-59 and 60+ years versus $<40$ years); practice location (rural, semi-rural, town/city and inner city versus suburban); patient type (deprived, mixed poor, mixed well-off and affluent versus average); practice size (singlehanded versus more than one doctor, and list size); practice contract (personal medical services (PMS) versus general medical services (GMS)); and individual contract status (salaried versus principal). Statistical significance of independent variables was evaluated at the $99 \%$ level $(P<0.01)$ to allow for the number of models tested.

\section{Analysis framework}

We describe the results in terms of our previously published conceptual framework for quality (Campbell et al., 2000) (Figure 1) which describes quality of care in terms of structure (the conduit through which care is delivered), process (the actual care given), and outcome (the consequence for patients and the health care system).

In this article, we look particularly at the relationships between the different facets of quality of care, and how changes in one are likely to lead to changes in the other. We also reflect that care is not made up of unconnected episodes, but rather includes care over time. We have therefore also considered the likely impact of the quality incentives on continuity of care, co-ordination and comprehensiveness of care. These are key and defining attributes of primary care (Starfield, 1992) that may be increasingly important as patients with multiple chronic conditions become an increasingly large part of general practice work (Starfield et al., 2003). 


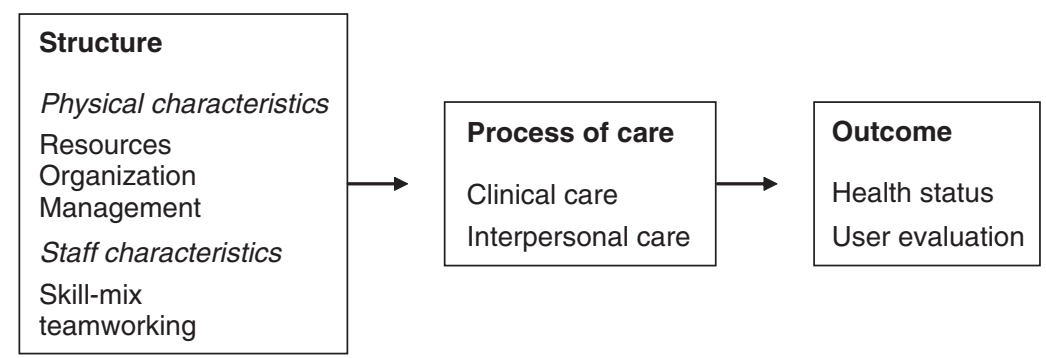

Figure 1 Components of quality of care (from Campbell et al., 2000)

\section{Results}

\section{Structure of primary care}

A number of GPs commented that financial incentives were strong motivators for GPs - ' $m y$ collective noun for GPs is a grasp of GPs' (GP55) and those interviewed confirmed that the new contract was producing major changes in the ways in which practice activity was structured. Most believed that these changes would improve quality of care for the incentivized conditions, but that practices with poor organization would be unable to respond to the incentives offered.

GPs reported significant changes in relation to the staff they were employing or intending to employ in their practices as a result of the new contract. These included increased employment of nurses, providing both nurse-led chronic disease management, and increased triage and management of minor illness by nurses. They also reported significant recruitment of data entry clerks to address the administrative work-load associated with the contract, and healthcare assistants to undertake a range of health promotion tasks.

GPs were generally positive about the reconfiguration of roles and responsibilities between themselves and the nurses they employed, and about the associated activities which included developing new clinics (eg, smoking cessation, diabetes, asthma), acquiring new equipment (eg, for spirometry), establishing recall systems for patients with chronic diseases, improving data collection and accuracy, and writing more protocols. GPs reported other types of changed interaction between clinical members of staff, most frequently in a positive light. Some indicated that the activities being rewarded were ones that they had being doing for some time:

And almost for the first time somebody's acknowledging that meeting regularly to discuss things that go wrong is something that, you know, is broadly speaking a good idea. But I mean we've been doing that for ten/twelve years.

(GP49)

GPs speculated that the changing professional roles signalled a move away from generalism towards specialization. They predicted, for example, that GPs would start working more like specialists, seeing only the more complex or sicker patients, while nurses treated minor illness and stable chronic disease. Other government policies concurrently provide opportunities for GPs to develop areas of clinical specialization:

So I think a move away from generalism to specialisation is a major theme of the new contract with it's specific reference to things like GPs with special interests and things like that ... which I do think is probably the demise of traditional general practice.

(GP21)

\section{Process of care}

All participants commented on the increased bureaucracy associated with the quality incentives, the need to develop clinical computing systems, and the need to record data in order to claim payments. Most practices were developing their methods of data collection, for example through increased use of clinical computing, development of computer templates, and a more systematic approach to clinical coding. Many feared that this would detract from other important aspects of care:

The inter-personal side is going to get less attention ... because the ticks in boxes are going to be more important, because they're 
going to constitute a greater proportion of our income, and therefore going to be more important to the consultation.

(GP25)

However, others welcomed these changes:

The key to the bulk of the contract is actually recording the data in a certain way on computer. I would argue that the recording of care is also part of good general practice.

(GP15)

Most participants welcomed the quality framework as a means of using evidence-based quality indicators to set minimum standards and to recognize and reward practices that provided good care. The previous payment system tended financially to penalize GPs who invested in their own practices:

unlike previous contracts it will hopefully reward the better GPs

(GP54)

the idea of putting the resources where the morbidity is strikes me as a big advance ... and I'm only sorry that it has been softened by the bleatings of those who've had it too soft for too long

(GP55)

However, several participants feared that the contract had the potential to undermine the core value of continuity of care provided by GPs. New developments would include clearer demarcation of specialist clinician roles within larger practices and greater emphasis on a team approach or nurse-led care.

and some things are not very easily measurable, and therefore those things might get worse. The classic thing of course, is to do with continuity of care ... it's quite possible in those sorts of areas there will be reductions in quality

(GP21)

Participants commented that primary care provision was becoming fragmented through other government policies, for example, the introduction of NHS Direct (a 24-hour nurse-led telephone advice service) and walk-in centres. This fragmentation could be increased within practices by the greater emphasis on organizing clinics around particular chronic diseases lead by more specialized multiprofessional teams. GPs also commented on the loss of continuity of care that would result from GPs giving up 24-hour responsibility for patient care and their belief that the quality incentives would tend to lead smaller practices to merge into larger groups.

Many participants felt that the contract was disproportionately reductionist with its emphasis on individual chronic diseases, as opposed to people with complex health needs or co-morbidity, and especially, the care of the whole person.

It will improve the management of chronic disease in our society by bringing GPs up to a minimum standard. It will not provide the care for the whole person. It doesn't allow that I have sat in this chair for over twenty years and I know my patients really well. It doesn't allow for that. You can't count that ... and you can't count the caring element.

(GP52)

An older GP commented that the contract ushered in 'the death of generalism and holistic care' (GP25), but another disagreed, describing how 'mercifully we've been able to put the clock back ... and get back to the people agenda' (GP55) by delegating tasks appropriately within a wider team freeing up his time to see other patients.

Concern was expressed for conditions not incentivized within the quality framework. While the indicators in the framework had broad support, the majority of GPs emphasized that general practice involves far more areas than the 'easily measured' indicators included in the framework. Un-incentivized areas mentioned included acute care, preventive care, care for specific groups such as children or the elderly, depression and other minor mental illnesses, interpersonal aspects of care, co-ordination of care, and patients with multiple co-morbidities.

There's no incentive to do anything about it is there, such as care of the elderly, because people are going to be fixated on things that are covered by the targets.

(GP8)

And I think the whole thing is geared far too much towards targets for common diseases and it is going to detract in a very major way from actually providing caring doctoring in primary care for our patients. 
Despite the view of some GPs that the neglect of certain aspects of care would be inevitable as a result of the incentive framework, others retained some degree of expectation that their own clinical priorities would not be affected:

I just hope that we are going to be able to administer the contract clinical side so that it becomes smooth running and that we carry on with the rest of the work as we have before, because it wouldn't be right to, you know, make any, the rest of it less important - it wouldn't be ethical.

(GP15)

\section{Outcomes of care}

As the interviews took place so soon after the introduction of the contract, they were focused mainly on changes taking place in practices, rather than on health outcomes, though GPs generally welcomed the incentive framework as a means of providing better evidence-based care for conditions with high morbidity. GPs made little reference to patient surveys, which form the major part of the patient experience incentives. This may be because patient surveys required little preparatory time and the first claims for surveys were not needed until April 2005, a year after our interviews.

\section{Quantitative survey findings}

The findings of the questionnaire survey broadly supported the results of the qualitative interviews. In relation to quality of care, the majority of GPs anticipated that the contract would improve preventive care and care for their patients with chronic conditions (Table 1). Respondents generally predicted little change in care for their patients with acute conditions or in the overall quality of care. However, in line with some of the qualitative reports, a substantial minority (31 and $36 \%$, respectively) expected these two aspects to deteriorate. In relation to their own working life, GPs felt that the contract would increase their administrative and clinical work-loads, while reducing their professional autonomy and the overall quality of their working life (Table 2).

Multivariate analysis indicated that there was generally little association between doctors' expectations of the new contract and their individual demographic, contract or practice characteristics, with few significant effects being found. Male doctors were less likely to think that the contract would increase their clinical work-load (odds ratio $(\mathrm{OR})=0.59,95 \%$ confidence interval $(\mathrm{CI}) 0.44$ $0.79, P<0.001)$, and salaried doctors were less likely to expect an increase in their administrative work-load (OR $=0.24, \mathrm{CI}=0.10-0.56, P<0.005)$. Doctors aged $40-49$ years $(\mathrm{OR}=0.60, \mathrm{CI}=0.42-$ $0.86, P<0.01)$ or $50-59$ years $(\mathrm{OR}=0.57, \mathrm{CI}=$ $0.39-0.84, P<0.01$ ) were more likely than younger doctors to anticipate a negative impact of the new contract on their autonomy, but doctors from town/ city practices were more likely than those from suburban practices to anticipate a positive impact $(\mathrm{OR}=2.10, \mathrm{CI}=1.47-2.99, P<0.001)$. Town/city doctors were also more likely than their suburban colleagues to be positive about the impact of the contract on their overall quality of working life $(\mathrm{OR}=1.63, \mathrm{CI}=1.16-2.31, P<0.01)$, as were doctors from rural practices $(\mathrm{OR}=2.28, \mathrm{CI}=1.33$ $3.90, P<0.005)$. There were no significant relations between any of these characteristics and doctors' views on whether aspects of quality of care would improve.

\section{Discussion}

While the practices were selected to maximize variation in practice type, the selection of individual GPs within practices was to some extent a convenience sample. The qualitative reports of GPs in the interviews were consistent with the quantitative data collected from the larger, nationally representative survey. However, the results still need to be regarded as preliminary, to be confirmed by empirical studies of the actual impact of the new financial incentives.

This study suggests that the financial incentives offered in the new GP contract are producing major changes in practice activity, and some aspects of the scheme appear to have broad support from GPs. For example, we found little criticism of the actual clinical indicators which were generally taken from national guidelines and might be expected to have broad professional support. Likewise, there was little direct criticism of the organizational indicators which were taken largely from quality improvement schemes developed by the Royal College of General Practitioners (2001), the main 
Table 1 Predicted effects of new contract on quality of care

\begin{tabular}{|c|c|c|c|c|c|c|c|}
\hline & \multirow[t]{2}{*}{$\begin{array}{l}\text { Number of } \\
\text { responses }\end{array}$} & \multicolumn{6}{|c|}{$\begin{array}{l}\text { Responses of GPs to question: 'Please indicate how you think the } \\
\text { new GMS contract will affect the following issues' }\end{array}$} \\
\hline & & $\begin{array}{l}\text { Decrease } \\
\text { a lot }\end{array}$ & $\begin{array}{l}\text { Decrease } \\
\text { a little }\end{array}$ & No change & $\begin{array}{l}\text { Increase } \\
\text { a little }\end{array}$ & $\begin{array}{l}\text { Increase } \\
\text { a lot }\end{array}$ & $\begin{array}{l}\text { Cannot } \\
\text { answer }\end{array}$ \\
\hline $\begin{array}{l}\text { Quality of care for patients with } \\
\text { chronic conditions }\end{array}$ & 1022 & $\begin{array}{l}27 \\
(2.6 \%)\end{array}$ & $\begin{array}{l}70 \\
(6.9 \%)\end{array}$ & $\begin{array}{l}218 \\
(21.3 \%)\end{array}$ & $\begin{array}{l}559 \\
(58.6 \%)\end{array}$ & $\begin{array}{l}124 \\
(13.9 \%)\end{array}$ & $\begin{array}{l}24 \\
(2.4 \%)\end{array}$ \\
\hline $\begin{array}{l}\text { Quality of care for patients with } \\
\text { acute conditions }\end{array}$ & 1021 & $\begin{array}{l}72 \\
(7.1 \%)\end{array}$ & $\begin{array}{l}245 \\
(24.0 \%)\end{array}$ & $\begin{array}{l}588 \\
(57.6 \%)\end{array}$ & $\begin{array}{l}67 \\
(6.6 \%)\end{array}$ & $\begin{array}{l}19 \\
(1.9 \%)\end{array}$ & $\begin{array}{l}30 \\
(2.9 \%)\end{array}$ \\
\hline Quality of preventive care & 1021 & $\begin{array}{l}19 \\
(1.9 \%)\end{array}$ & $\begin{array}{l}41 \\
(4.0 \%)\end{array}$ & $\begin{array}{l}276 \\
(27.0 \%)\end{array}$ & $\begin{array}{l}543 \\
(53.2 \%)\end{array}$ & $\begin{array}{l}115 \\
(11.3 \%)\end{array}$ & $\begin{array}{l}27 \\
(2.6 \%)\end{array}$ \\
\hline Overall quality of care & 1020 & $\begin{array}{l}25 \\
(24.5 \%)\end{array}$ & $\begin{array}{l}118 \\
(11.6 \%)\end{array}$ & $\begin{array}{l}411 \\
(40.3 \%)\end{array}$ & $\begin{array}{l}379 \\
(37.2 \%)\end{array}$ & $\begin{array}{l}44 \\
(4.3 \%)\end{array}$ & $\begin{array}{l}43 \\
(4.2 \%)\end{array}$ \\
\hline
\end{tabular}

Table 2 Predicted effects of new contract on GP worklife

\begin{tabular}{|c|c|c|c|c|c|c|c|}
\hline & \multirow[t]{2}{*}{$\begin{array}{l}\text { Number of } \\
\text { responses }\end{array}$} & \multicolumn{6}{|c|}{$\begin{array}{l}\text { Responses of GPs to question: 'Please indicate how you think the new } \\
\text { GMS contract will affect the following issues' }\end{array}$} \\
\hline & & $\begin{array}{l}\text { Decrease } \\
\text { a lot }\end{array}$ & $\begin{array}{l}\text { Decrease } \\
\text { a little }\end{array}$ & No change & $\begin{array}{l}\text { Increase } \\
\text { a little }\end{array}$ & $\begin{array}{l}\text { Increase } \\
\text { a lot }\end{array}$ & $\begin{array}{l}\text { Cannot } \\
\text { answer }\end{array}$ \\
\hline Professional autonomy & 1020 & $\begin{array}{l}397 \\
(38.9 \%)\end{array}$ & $\begin{array}{l}421 \\
(41.3 \%)\end{array}$ & $\begin{array}{l}124 \\
(12.2 \%)\end{array}$ & $\begin{array}{l}24 \\
(2.4 \%)\end{array}$ & $\begin{array}{l}8 \\
(0.8 \%)\end{array}$ & $\begin{array}{l}46 \\
(4.5 \%)\end{array}$ \\
\hline Administrative work-load & 1020 & $\begin{array}{l}1 \\
(0.1 \%)\end{array}$ & $\begin{array}{l}5 \\
(0.5 \%)\end{array}$ & $\begin{array}{l}37 \\
(3.6 \%)\end{array}$ & $\begin{array}{l}192 \\
(18.8 \%)\end{array}$ & $\begin{array}{l}765 \\
(75.0 \%)\end{array}$ & $\begin{array}{l}20 \\
(2.0 \%)\end{array}$ \\
\hline Clinical work-load & 1018 & $\begin{array}{l}5 \\
(0.5 \%)\end{array}$ & $\begin{array}{l}15 \\
(1.5 \%)\end{array}$ & $\begin{array}{l}80 \\
(7.8 \%)\end{array}$ & $\begin{array}{l}296 \\
(29.0 \%)\end{array}$ & $\begin{array}{l}598 \\
(58.6 \%)\end{array}$ & $\begin{array}{l}24 \\
(2.4 \%)\end{array}$ \\
\hline Overall quality of working life & 1014 & $\begin{array}{l}184 \\
(18.2 \%)\end{array}$ & $\begin{array}{l}367 \\
(36.2 \%)\end{array}$ & $\begin{array}{l}234 \\
(22.9 \%)\end{array}$ & $\begin{array}{l}131 \\
(12.9 \%)\end{array}$ & $\begin{array}{l}25 \\
(2.5 \%)\end{array}$ & $\begin{array}{l}73 \\
(7.2 \%)\end{array}$ \\
\hline
\end{tabular}

professional body for GPs. The main criticisms directed at the incentive scheme by the GPs were towards the increased administrative work-load and the potential unintended consequences of the incentives.

The interviews demonstrated that significant structural changes were taking place within practices as a result of the incentives, in particular the employment of more nurses. This continues a trend seen over many years. A series of reforms to payment systems for GPs, beginning in 1966, has made it financially sensible for GPs to employ nurses to deliver key primary care services, particularly in the areas of health promotion, population health screening and chronic disease management. Nurses are seen as increasingly important in chronic disease management, and the growth of nursing in general practice commands broad professional support. These interviews confirm the general support for the expansion of nursing roles and responsibilities within general practice.
However, while the management of medical conditions has always been accepted as an important part of the work of GPs, it is not in fact what defines their discipline. Biomedical approaches to illness are the responsibility of all doctors, but GPs have asserted the defining features of their discipline in terms of other characteristics, in particular, viewing the patient as a whole (including a biopsychosocial model of illness), developing long-term relationships with patients, providing longitudinal continuity of care, and providing high quality interpersonal care. These features have been articulated by a number of professional leaders (Heath, 1990; Starfield, 1992; London: RCGP, GPC, NHS Alliance, 2001; Pereira Gray et al., 2003).

Two aspects of care stand out from the interviews as being a cause for concern. The first is the risk that care for un-incentivized conditions or aspects of care may get worse. Many of our respondents raised this as a concern, even though almost all felt that their own personal priorities would not be affected. 
If this effect is seen, it is unlikely to be a deliberate one, but as one doctor said in our previous study of a local quality improvement scheme:

I think our attitude is certainly more mechanistic for that particular patient for quite a good deal of the consultation time - 'BP is so and so therefore you the patient have to change your medication and come back next week' - and so much less in the way of communication about how he feels about the disease or the treatment or management.

(Spooner et al., 2001)

Doctors in this study were clearly concerned about the risk that the focus on biomedical targets would reduce the importance of other aspects of care, and their ability to treat the patient as a 'whole person'.

The second major concern related not to individual episodes of care, but to the impact of the financial incentives on care given over time, and in particular on continuity and co-ordination of care, which are core values of family practice. Doctors in this study were most concerned about the impact of the contract on personal or relational continuity. Having a doctor who is known and trusted is highly valued by patients especially when they have serious or psychological problems (Kearley et al., 2001). For doctors, a long-term relationship makes management easier (Hjortdahl and Borchgreink, 1997; Mainous et al., 2001; Pereira Gray et al., 2003; Tarrant et al., 2003) and may reduce the opportunity for medical error (Freeman and Hjortdahl, 1991; Dovey et al., 2002). Changes resulting from the financial incentive scheme include larger teams. Larger team size is known to reduce personal continuity of care (Schers et al., 2002; Wensing et al., 2002) and make the co-ordination of care more difficult (Barr, 1995). In addition, there is increased delegation from GPs to specialized members of staff - for example, to a nurse specializing in diabetes care. For some doctors, this creeping specialization was seen as 'the demise of the traditional GP', even though it is GPs themselves who have promoted the development of disease-based clinics within family practice as a means of improving quality of care. These developments also occur at a time when other changes in the NHS including new points of contact such as NHS Direct, and walk-in centres provide further opportunities for patients to have contact with multiple providers. These wider developments increase the likelihood of fragmentation and poor co-ordination of care.

GPs were also concerned at the potential negative impact the incentives might have on internal professional drivers. External incentives can reduce internal or moral motivation, but they can also reinforce internal motivation if they convey positive information to physicians about their competence (the so-called attributional effect (Deci et al., 1999)). In terms of Frey's analysis (Frey, 1997) the overall impact may depend on whether the incentives reduce or 'crowd out' internal motivation, or whether they enhance internal motivation ('crowding in'). Our data suggest that both effects could occur. In summary our findings suggest that while the new payment incentives may improve the quality of care for incentivized chronic diseases, there is a risk that other aspects of care, and some core motivating values of GPs could be damaged.

The quality framework described in this article is one part of a wider programme to improve quality of health and social care in the UK, which Leatherman and Sutherland have described as 'the world's most ambitious, comprehensive, systematic, and intentionally funded effort ... for improving the quality of a nation's health care system (Leatherman and Sutherland, 2003). Their initial evaluation suggests that the effects, including those in primary care, have been broadly positive (Roland and Smith, 2003). The size of financial incentives offered in the present quality framework suggests that there will be continued, and possibly rapid, movement towards achieving the intended outcomes of the scheme. The overall balance of benefit will depend on the extent to which unintended consequences occur, and we have identified concerns about possible negative effects from the psychological (Deci et al., 1999); sociological (Harrison and Smith, 2004), and economic (Frey, 1997) literatures. The quality of care in the NHS in the future will continue to depend substantially on the professional motivation of its physicians and nurses. Overall, GPs believe the new contract will have a positive affect on their quality of care in targeted areas but an adverse affect on their professional autonomy and work-load, with little variation in this view across GPs with different demographic or practice characteristics. 


\section{References}

Baker, D. and Middleton, E. 2003: Cervical screening and health inequality in England in the 1990s. Journal of Epidemiology and Community Health 57, 417-23.

Barr, D.A. 1995: The effects of organizational structure on primary care outcomes under managed care. Annals of Internal Medicine 122, 353-59.

Campbell, S., Roland, M. and Buetow, S. 2000: Defining quality of care. Social Science and Medicine 51,1611-25.

Casalino, L.P. 1999: The unintended consequences of measuring quality on the quality of medical care. New England Journal of Medicine 341,1147-50.

Chaix-Couturier, C., Holtzer, C., Phillips, K.A., DurandZaleski, I. and Stansell, J. 2000: Effects of financial incentives on medical practice: results from a systematic review of the literature and methodological issues. International Journal of Quality in Health Care 12,133-42.

Checkland, K., Marshall, M. and Harrison, S. 2004: Rethinking accountability: trust versus confidence in medical practice. Quality and Safety in Health Care 13, 130-35.

Deci, E., Koestner, R. and Ryan, R. 1999: A meta-analytic review of experiments examining the effects on extrinsic rewards on intrinsic motivation Psychological Bulletin 125, 627-88.

Dovey, S.M., Meyers, D.S., Phillips, R.L., Green, L.A., Fryer, G.E., Galliher, J.M., Kappus, J. and Grob, P. 2002: A preliminary taxonomy of medical errors in family practice. Quality and Safety in Health Care 11, 233-38.

Freeman, G. and Hjortdahl, P. 1997: What future for continuity of care in general practice? British Medical Journal 314,1870-73.

Frey, B.S. 1997: Not just for the money: an economic theory of personal motivation. Cheltenham, UK: Edward Elgar Publishing.

Harrison, S. and Smith, C. 2004: Trust and moral motivation: redundant resources in health and social care? Policy and Politics 32, 371-86.

Heath, I. 1990: The mystery of general practice. London: Nuffield Provincial Hospitals Trust.

Hjortdahl, P. and Borchgreink, C.F. 1991: Continuity of care: influence of general practitioners' knowledge about their patients on use of resources in consultations. British Medical Journal 303, 1181-84.

Institute of Medicine (Committee on Quality of Health Care in America). 2001: Crossing the Quality Chasm: a new health system for the 21st century. Washington, DC: National Academy Press.

Kearley, K.E., Freeman, K.G. and Heath, A. 2001: An exploration of the value of the personal doctor-patient relationship in general practice. British Journal of General Practice 51,712-18.

Leatherman, S. and Sutherland, K. 2003: A quest for quality in the NHS. London: Nuffield Trust and the Stationary Office.

Mainous, A.G., Baker, R., Love, M., Periera Gray, D.J. and Gill, J.M. 2001: Continuity of care and trust in one's physician: evidence from primary care in the US and UK. Family Medicine 33, 22-27.
Middleton, E. and Baker, D. 2003: Comparison of social distribution of immunisation with measles, mumps, and rubella vaccine, England 1991-2001. British Medical Journal 326, 854.

Pereira Gray, D., Evans, P., Sweeney, K., Lings, P., Seamark, D. and Seamark, C. 2003: Towards a theory of continuity of care. Journal of the Royal Society of Medicine 96, 160-66.

Rizzo, J.A. and Blumenthal, J.A. 1996: Is the target income hypothesis an economic heresy? Medical Care Research Review 53, 243-66.

Rizzo, J.A. and Zeckhauser, R.J. 2003: Reference incomes, loss aversion and physician behaviour. Review of Economics and Statistics 85, 909-22.

Roland, M. 2004: Linking physicians' pay to the quality of care a major experiment in the United Kingdom. New England Journal of Medicine 351, 1448-54.

Roland, M.O. and Smith, J. 2003: The role and contribution of Primary Care Trusts to quality improvement. In Leatherman S. and Sutherland K. editors, The Quest for Quality in the NHS. London: The Nuffield Trust and The Stationary Office, 203-24.

Royal College of General Practitioners, General Practitioners Committee, NHS Alliance. 2001: Valuing general practice. London: RCGP, GPC, NHS Alliance.

Seddon, M.E., Marshall, M.N., Campbell, S.M. and Roland, M.O. 2001: Systematic review of quality of clinical care in general practice in the UK, Australia and New Zealand. Quality in Health Care 10, 152-58.

Sheaff, R. and Lloyd-Kendall, A. 2000: Principal-agent relationships in general practice: the first wave of English Personal Medical Services pilot contracts. Journal of Health Services Research and Policy 5, 156-63.

Smith, P. 1995: On the unintended consequences of publishing performance data in the public sector. International Journal of Public Administration 18, 277-310.

Spooner, A., Chapple, A. and Roland, M. 2001: What makes British general practitioners take part in a quality improvement scheme? Journal of Health Services Research and Policy 6, 145-50.

Starfield, B. 1992: Primary Care: concept, evaluation and policy. New York: Oxford University Press.

Starfield, B., Lenke, K.W., Bernhardt, T., Foldes, S.S., Forrest, C.B. and Weiner, J.P. 2003: Co-morbidity: Implications for the importance of primary care in 'case' management. Annals of Family Medicine 1, 8-14.

Tarrant, C., Stokes, T. and Baker, R. 2003: Factors associated with patients' trust in their general practitioner: a crosssectional survey. British Journal of General Practice 53, 798-800.

Wensing, M., Vedsted, P., Kersnik, J., Peersman, W., Klingenberg, A., Hearnshaw, H., Hjortdahl, P., Paulus, D., Künzi, B., Mendive, J. and Grol, R. 2002: Patient satisfaction with availability of general practice: an international comparison. International Journal for Quality in Health Care 14, $111-18$. 